\title{
Training General Practitioners and Medical Assistants Within the Framework of HoPES3, a Holistic Care Program for Elderly Patients to Integrate Spiritual Needs, Social Activity, and Self-Care into Disease Management in Primary Care
}

\author{
Elke Kunsmann-Leutiger, ${ }^{1, *}$ \\ Cornelia Straßner, ${ }^{2, *}$ Friederike \\ Schalhorn, ${ }^{3}$ Regina Stolz, $\mathbb{D}^{3}$ \\ Gabriele Stotz-Ingenlath,' \\ Nicola Buhlinger-Göpfarth, ${ }^{2}$ \\ Martina Bentner, ${ }^{2}$ Stefanie Joos, ${ }^{3}$ \\ Jan Valentini, ${ }^{3}$ Eckhard Frick (D) \\ 'Department of Psychosomatic Medicine \\ and Psychotherapy, Technical University of \\ Munich, Munich, Germany; ${ }^{2}$ Department of \\ General Practice and Health Services \\ Research, University Hospital Heidelberg, \\ Heidelberg, Germany; ${ }^{3}$ Institute of General \\ Practice and Interprofessional Care, \\ University Hospital Tübingen, Tübingen, \\ Germany \\ *These authors contributed equally to this \\ work
}

Background: This study presents a concept for training general practitioners (GPs) in taking a spiritual history. In the same workshop, medical assistants (MAs) were trained in counselling elderly, chronically ill patients on social activities and home remedies. After the training, GPs and MAs will apply the acquired skills in their practices within the scope of the HoPES3 intervention study, which aims at raising patients' self-efficacy.

Methods: Sixteen GPs and 18 MAs were trained in a 5-hour workshop and completed an evaluation questionnaire.

Results: All participants reported great satisfaction. In particular, $85 \%$ of GPs $(n=11)$ affirmed increased capacity to address patients' spiritual needs. About $88 \%(n=15)$ of MAs were satisfied with the training, yet expressed difficulties in integrating theoretical knowledge into daily professional routine.

Discussion: While the evaluation of the workshop is promising, the results of the randomizedcontrolled trial evaluating the effectiveness of the complete HoPES3 intervention have to be awaited.

Conclusion: To our knowledge, this is the first interdisciplinary, holistic care training in primary care in Germany. It fosters GPs' and MAs' competency in providing a proactive support in spirituality, social activities, and home remedies to their patients. If the concept proves to be effective, it could be integrated into existing care models and curriculums and provide clear guidance on how to consider elderly patients' spiritual needs and strengthen their self-efficacy in primary care settings.

Keywords: primary care, spiritual care, holistic care, elderly patients, medical assistents

\section{Introduction}

It is well known that elderly, multimorbid patients with polypharmacy frequently experience a high disease burden and low quality of life. Therefore, improving the care of particularly this patient group is of great importance. However, often GPs apply evidence-based knowledge mainly in order to present undesired events such as falls or delirium. While the importance of such measures is undeniable, there is a risk of overlooking other dimensions of care. For example,
Correspondence: Eckhard Frick

Department of Psychosomatic Medicine and Psychotherapy, Technical University of Munich, Langerstrasse 3, München,

81675, Germany

Tel +498923862230

Fax +498923862402

Email eckhard.frick@tum.de 
there is evidence that self-efficacy, i.e., the belief in one's own ability to reach personal goals, is a decisive factor for elderly patients' quality of life. ${ }^{1}$

We argue that a more holistic approach for the care of elderly, chronically ill patients is needed which considers three aspects strongly linked to self-efficacy: patients' spiritual needs, social activity and self-care, i.e., patients' activeness in areas that can enhance well-being other than taking medication. ${ }^{2-4}$

Studies show that patients have voiced the wish for holistic attention from their physician, ${ }^{5,6}$ while many GPs acknowledge that meeting these needs should be an integral part of primary care. ${ }^{4,-9}$ At the same time, patients and GPs alike report a lack in competencies on the part of the physician in terms of providing holistic primary care, in particular in meeting patients' spiritual needs. ${ }^{10}$ Insufficient training offered in the medical school curriculum, as well as in continuous medical education seems to be a major part of the problem. ${ }^{1-14}$ In addition, studies show that working in interprofessional teams- such as can be the case between GPs and MAs in a primary care setting- contributes to a holistic approach in patient care and can greatly enhance health care provision. ${ }^{15}$

Within the scope of the "Holistic Care Program for Elderly Patients to Integrate Spiritual Needs, Social Activity and Self-Care into Disease Management in Primary Care" (HoPES3), GPs conducted a spiritual needs assessment. ${ }^{2,16}$ If a need for more social contact and/or self-care was identified, MAs would advise patients on social activities in their regions and on selfcare options, particularly on the application of home remedies. The above mentioned interventions were taught in a 5-hour workshop which was one essential element in this complex intervention study, following MRC guidelines. $^{16}$

This paper summarizes the concept, implementation and evaluation of the workshop, focusing on the following research questions:

1. Is the training concept feasible, i.e., could the workshop be conducted as planned?

2. How is the acceptance of the training, i.e., how was the training perceived by GPs and MAs?

3. What modifications could be made to improve the training concept?

\section{Methods}

\section{Study Design}

This manuscript reports the content, course and evaluation of a workshop for GPs and MAs assigned to the intervention group of the HoPES3 study.

\section{Participants and Setting}

16 GPs and 18 MAs participated in the training. The participants had previously been recruited for the HoPES3 study from GP practices in the area of Heidelberg and Tübingen, Germany and were randomly assigned to the intervention group. Details about the recruitment are described in the study protocol.

\section{Intervention: Content and Course of the Workshop Learning Objectives and Teaching Methods}

The HoPES3 study team had designed the training program based on established teaching methods frequently used in the medical curriculum. ${ }^{5,11,17}$ For GPs and MAs alike, the goal was to raise awareness for holistic primary care, to provide fundamental knowledge, to enhance communication skills, ${ }^{18}$ and to teach practical skills for the interventions for the HoPES3 study. For GPs in particular, the learning objectives included acquiring practical skills in spiritual history taking and becoming aware of one's own attitude toward spirituality. From the literature, we know that engaging in self-reflection in small groups can contribute to an increase in spiritual awareness. ${ }^{5,11,19}$ In addition, physicians' reflections on their own spirituality or attitude towards it enhances the skills of taking a spiritual history. ${ }^{5,11,17,19}$ For MAs, specific learning objectives included being trained in consulting patients on appropriate social activity offers and in the use of home remedies.

\section{Introduction of GPs, MAs and the HoPES3 Study Team}

Following the introduction of participants and the HoPES3 team, each person was asked to share his or her own personal attitude toward spirituality, using a metaphor: "Spirituality, for me, is like ...". We then proceeded to explain the theoretical background of the HoPES3 study and the interventions to be delivered to patients by GPs and MAs. A 10-minute movie was shown, demonstrating the prevalence and consequences of loneliness in the 
elderly. Furthermore, the concept of "social prescribing" in the UK was presented as a "best-practice-example" in the movie. ${ }^{20}$ After this introduction, GPs and MAs were separated into two groups and rooms, respectively.

\section{Training GPs in Spiritual History Taking} Introduction to the Interview Schedule, SPIR

Following a short, introductory lecture in Spiritual Care, GPs were instructed on how to assess patients' spiritual needs, using the previously tested semi-structured interview schedule, SPIR ${ }^{21}$ based on Puchalski's spiritual interview schedule, FICA ${ }^{19}$. With the SPIR (see Supplement 1) patients are questioned directly to their spiritual orientation. By doing so, the SPIR takes on a proactive, interventional character. Additionally, a videotaped interview was shown, giving the group an idea of how to apply the SPIR in a clinical setting. Participants received prepared documentation sheets and were asked to document the spiritual assessment viewed in the video.

\section{Group Exercise and Self-Awareness}

In order to get acquainted with the interview schedule and to reflect on own spiritual awareness, GPs formed small groups of three and practiced the SPIR and documentation on each other, rotating in their roles of interviewer, interviewee and observer. After each round, there was time for a shared silence moment and for feedback.

\section{Work with Standardized Patients}

Finally, GPs gathered together as a whole group for working with standardized patients: GPs had the chance to practice the SPIR in a simulated consultation. For this purpose, standardized patients had been trained by the HoPES3 team prior to the workshop. We developed four different characters, which represented typical, yet varying patient types in the GP practice. These patients differed in their spiritual orientations and the degree of physical impairment (see Supplement 2 for a detailed description of the four character roles). Following each simulated consultation, there was time for giving and receiving feedback in the whole group round.

\section{Training MAs in Counselling on Social Activities and Home Remedies \\ Talking About Loneliness}

MAs received basic information on the causes and consequences of loneliness in old age and were made aware that talking about loneliness is a sensitive issue. Two opposing scenes were shown on video, one with positive, empowering MA-patient-interaction and one with a negative, patronizing communication form. Afterwards, the principles of "Motivational Interviewing" (to create a trustful atmosphere, to ask permission to give patient advice, to elicit the patients' motivation for change, and to plan change mutually) were introduced. Following this, MAs were asked to reflect these principles and how they may be applied in their daily interactions with patients.

\section{Web-Portal and Role Play on Patient Counselling}

As part of the HoPES3 intervention, practices as well as patients will receive access to a web-portal which comprises a database with social offers for seniors in the region of the practice. MAs received tablet computers and were instructed in the functions of the database. Afterwards, MAs received a description of a fictional patient and practiced a conversation about loneliness and social activities in pairs.

\section{Home Remedy Leaflets}

Finally, the MAs received a training on the use of home remedies and other self-care interventions. Nine typical complaints of elderly patients, such as joint pains, cold feet, slight cough, headaches, backache, sleeplessness, vertigo and obstipation and their related home remedies were selected on the basis of a literature search and established guidelines in complementary care following the Delphi method. User-optimized information leaflets for these nine common disorders and seventeen appropriate home remedies were developed.

\section{Joint Closing with GPs and MAs}

In this final part of the training, the HoPES3 team, GPs, and MAs discussed the process of implementing the interventions into their individual practice routines.

\section{Data Collection}

After the joint closing, all participants were asked to evaluate the training. GPs and MAs received two different, two-page self-developed questionnaires which used a Likert scale and additional free text answer options to obtain feedback on the general learning achievements and on individual aspects of the training. The items of the questionnaires are presented in Tables 1 and 2. In addition, impressions gathered from the whole group feedback rounds following each simulated consultation in the GP training were documented.

\section{Data Analysis}

The data were analyzed descriptively (means and percentages). We report English translations of the participants' free texts. 
Table I Evaluation of the Training by GPs

\begin{tabular}{|c|c|c|c|c|c|}
\hline General Learning Achievement & $\begin{array}{c}\text { Strongly } \\
\text { Disagree \% (n) }\end{array}$ & $\begin{array}{c}\text { Somewhat } \\
\text { Disagree \% (n) }\end{array}$ & $\begin{array}{l}\text { Somewhat Agree } \\
\%(\mathbf{n})\end{array}$ & $\begin{array}{c}\text { Strongly } \\
\text { Agree \% (n) }\end{array}$ & $\begin{array}{l}\text { No Answer } \\
\%(n)\end{array}$ \\
\hline I learned how to address the spiritual needs of patients & 0 & $8(1)$ & $31(4)$ & $54(7)$ & $8(1)$ \\
\hline SPIR is a good and helpful spiritual schedule & 0 & 0 & $39(5)$ & $62(8)$ & 0 \\
\hline $\begin{array}{l}\text { I learned how to document patients' existential/spiritual/ } \\
\text { religious needs }\end{array}$ & 0 & 0 & $69(9)$ & $15(2)$ & $15(2)$ \\
\hline $\begin{array}{l}\text { Practicing SPIR in groups of three was helpful } \\
\ldots \text { as interviewer } \\
\ldots \text { as interviewee } \\
\ldots \text { as observer }\end{array}$ & $\begin{array}{l}0 \\
0 \\
0\end{array}$ & $\begin{array}{c}0 \\
8(1) \\
0\end{array}$ & $\begin{array}{l}23(3) \\
23(3) \\
46(6)\end{array}$ & $\begin{array}{l}77(10) \\
69(9) \\
39(5)\end{array}$ & $\begin{array}{c}0 \\
0 \\
15(2)\end{array}$ \\
\hline $\begin{array}{l}\text { Practicing with standardized patients was helpful and } \\
\text { useful }\end{array}$ & 0 & 0 & $8(1)$ & $92(12)$ & 0 \\
\hline $\begin{array}{l}\text { The feedback round following the exercise with } \\
\text { standardized patients was useful }\end{array}$ & 0 & 0 & $31(4)$ & $69(9)$ & 0 \\
\hline $\begin{array}{l}\text { I can imagine using the SPIR with patients beyond the time } \\
\text { frame of this study }\end{array}$ & 0 & 0 & $46(6)$ & $54(7)$ & 0 \\
\hline $\begin{array}{l}\text { The training made me become more aware of my own } \\
\text { spirituality }\end{array}$ & $8(1)$ & $8(1)$ & $54(7)$ & $31(4)$ & 0 \\
\hline $\begin{array}{l}\text { I am able to implement the study concept into my daily } \\
\text { professional routine }\end{array}$ & 0 & 0 & $62(8)$ & $39(5)$ & 0 \\
\hline Individual Aspects of the Training & $\begin{array}{l}\text { Dissatisfied \% } \\
\text { (n) }\end{array}$ & $\begin{array}{c}\text { Somewhat } \\
\text { Dissatisfied \% (n) }\end{array}$ & $\begin{array}{c}\text { Somewhat } \\
\text { Satisfied \% (n) }\end{array}$ & $\begin{array}{l}\text { Fully Satisfied } \\
\qquad \%(n)\end{array}$ & $\begin{array}{l}\text { No Answer } \\
\%(n)\end{array}$ \\
\hline Information content & 0 & 0 & $31(4)$ & $69(9)$ & 0 \\
\hline Presentation (Didactics, etc.) & 0 & 0 & $23(3)$ & $77(10)$ & 0 \\
\hline Opportunities to participate & 0 & 0 & $8(1)$ & $92(12)$ & 0 \\
\hline Work atmosphere & 0 & 0 & $23(3)$ & $77(10)$ & 0 \\
\hline Practicality/applicability & 0 & 0 & $31(4)$ & $69(9)$ & 0 \\
\hline Organisation & 0 & 0 & $31(4)$ & $69(9)$ & 0 \\
\hline Material & 0 & 0 & $54(7)$ & $46(6)$ & 0 \\
\hline Cooperative communication/exchange & 0 & 0 & $15(2)$ & $85(11)$ & 0 \\
\hline How satisfied are you with the workshop on the whole? & 0 & 0 & $23(3)$ & $77(10)$ & 0 \\
\hline
\end{tabular}

\section{Results}

\section{Characteristics of the Participants}

Table 3 shows the characteristics of the workshop participants. On average, GPs were 53 (range 36-64) years old with an average work experience of 23 years; $33 \%$ $(n=5)$ had additional qualifications in naturopathic treatment. MAs were 45 (range 20-55) years old on average with an average work experience of 19 years. All GPs and MAs were of either Christian or non-religious affiliation.

\section{Results of the Survey Evaluation by GPs}

13 of the 16 participating GPs completed the evaluation questionnaire (response rate $81 \%$ ).

As Table 1 shows, $100 \%(\mathrm{n}=13)$ of GPs found the SPIR interview schedule somewhat or strongly helpful in taking a spiritual history. In fact, $100 \%(\mathrm{n}=13)$ could envision using the SPIR schedule with their patients beyond the time frame of the HoPES3 study. Eighty-five percent $(\mathrm{n}=11)$ somewhat or strongly agreed to have learned how to address spiritual needs 
Table 2 GPs' Free-Texts (Examples)

\begin{tabular}{|l|}
\hline - "Getting started was a problem" \\
\hline $\begin{array}{l}\text { "Addressing spirituality directly was difficult because it is a very intimate part } \\
\text { of the patient" }\end{array}$ \\
\hline - "Beginning the spiritual history, explaining to the patient what is meant by \\
spirituality, without him or her feeling confronted" \\
\hline - "The academic approach to spirituality is difficult for me" \\
- "So far I have never addressed spirituality so forcefully" \\
\hline "Throwing the first stone into the water was hard" \\
\hline "Documentation was the most difficult part" \\
\hline "Self-awareness! Yet, who dares to think aloud, learns quite a bit about \\
himself/herself"
\end{tabular}

with their patients and $100 \%(\mathrm{n}=13)$ stated that they learned how they could implement the study concept into the daily professional routine. One further objective of the training was to promote self-awareness in terms of own spirituality. Here $16 \%(\mathrm{n}=2)$ felt that this goal was not achieved. The work with standardized patients was considered helpful by all GPs, with $92 \%(n=12)$ strongly agreeing to this. In terms of individual aspects of the training schedule including didactics, work atmosphere, organization and training material, all GPs were satisfied, with $77 \%$ being fully and $23 \%$ somewhat satisfied. Table 2 shows some of the participating GPs' free-texts.

\section{Evaluation by MAs}

17 of the 18 MAs participating in the training completed the evaluation questionnaire (response rate 94\%) (Table 4).

Concerning the theoretical input, $82 \%(n=14)$ of MAs agreed to have learned a lot about loneliness in the elderly and about self-care. Regarding the practical competencies, $77 \%(n=13)$ of MAs stated that they learned a lot about instructing patients in the use of home remedies, but only $53 \%(\mathrm{n}=9)$ agreed that they learned a lot about advising patients on social activity. It was interesting, that $41 \%(n=7)$ MAs did not answer this question, and generally, MAs skipped more questions than GPs. The majority of MAs $(88 \%, n=15)$ stated that they felt capable to implement the HoPES3 interventions into practice after the training.

\section{Discussion}

The aim of this study was to examine the feasibility and acceptance of a holistic care training for GPs and MAs in
Table 3 Characteristics of the Participants

\begin{tabular}{|c|c|c|}
\hline & GP & MA \\
\hline Number of participants & $\mathrm{n}=15^{\mathrm{a}}$ & $\mathrm{n}=18$ \\
\hline Age, years, mean (range) & $53(36-64)$ & $45(20-55)$ \\
\hline Gender (female) & $47 \%(n=7)$ & $100 \%(n=18)$ \\
\hline Religious affiliation & & \\
\hline Protestant & $47 \%(n=7)$ & $44 \%(n=8)$ \\
\hline Catholic & $13 \%(n=2)$ & $39 \%(n=7)$ \\
\hline Muslim & 0 & 0 \\
\hline Other & 0 & 0 \\
\hline None & $40 \%(n=6)$ & $17 \%(n=3)$ \\
\hline Marital status & & \\
\hline Single & 0 & $17 \%(n=3)$ \\
\hline In partnership/married & $93 \%(n=14)$ & $83 \%(n=15)$ \\
\hline Missing data & $7 \%(n=1)$ & 0 \\
\hline Practice model & & \\
\hline Single-person practice & $40 \%(n=6)$ & $56 \%(n=10)$ \\
\hline Practice cooperation & $60 \%(n=9)$ & $44 \%(n=8)$ \\
\hline $\begin{array}{l}\text { Work experience, years } \\
\text { (range) }\end{array}$ & $23(4-40)$ & $19(1-35)$ \\
\hline $\begin{array}{l}\text { Average weekly working } \\
\text { hours in hours, (range) }\end{array}$ & $48(20-75)$ & $30(19-40)$ \\
\hline Additional medical titles & & \\
\hline None & $33 \%(n=5)$ & \\
\hline Manual medicine & $13 \%(n=2)$ & \\
\hline Acupuncture & $13 \%(n=2)$ & \\
\hline Homeopathy & $7 \%(n=1)$ & \\
\hline Naturopathy & $33 \%(n=5)$ & \\
\hline Other & $33 \%(n=5)$ & \\
\hline $\begin{array}{l}\text { Anthroposophical } \\
\text { medicine }\end{array}$ & $7 \%(n=1)$ & \\
\hline Nutritional medicine & $7 \%(n=1)$ & \\
\hline Clinical geriatrics & $7 \%(n=1)$ & \\
\hline Psychotherapy & $7 \%(n=1)$ & \\
\hline Palliative Care & $7 \%(n=1)$ & \\
\hline
\end{tabular}

Note: ${ }^{2} 16$ GPs were trained in the workshop, however we did not obtain the demographic data from one GP.

preparation for the interventional phase of the HoPES3 study and to deduce possible modifications to improve the training concept.

\section{Modifications Related to the Feasibility of the Training}

Regarding feasibility, our study confirms that the interprofessional, holistic care training was, for the most part, delivered as planned. The learning objectives may, however, have been a bit ambitious for a 5-hour workshop. Thus, the workshop may possibly profit from an extension of the length of the training. At the same time, prolonging the training time may reduce the 
Table 4 Evaluation of the Workshop by MAs

\begin{tabular}{|c|c|c|c|c|c|}
\hline Prior Knowledge & $\begin{array}{l}\text { Very Unsure } \\
\quad \%(n)\end{array}$ & $\begin{array}{l}\text { Somewhat } \\
\text { Unsure \% (n) }\end{array}$ & $\begin{array}{l}\text { Somewhat Sure } \\
\%(n)\end{array}$ & $\begin{array}{l}\text { Very Sure \% } \\
\text { (n) }\end{array}$ & $\begin{array}{l}\text { No Answer } \\
\%(n)\end{array}$ \\
\hline $\begin{array}{l}\text { How sure did you feel counselling elder patients in social } \\
\text { activity before the workshop? }\end{array}$ & 0 & $35(6)$ & $59(10)$ & $6(1)$ & 0 \\
\hline $\begin{array}{l}\text { How sure did you feel advising patients in the use of home } \\
\text { remedies before the workshop? }\end{array}$ & $6(1)$ & $47(8)$ & $35(6)$ & $12(2)$ & 0 \\
\hline General Learning Achievement & $\begin{array}{c}\text { Strongly } \\
\text { Disagree \% (n) }\end{array}$ & $\begin{array}{c}\text { Somewhat } \\
\text { Disagree \% (n) }\end{array}$ & $\begin{array}{l}\text { Somewhat } \\
\text { Agree \% (n) }\end{array}$ & $\begin{array}{c}\text { Strongly } \\
\text { Agree \% (n) }\end{array}$ & $\begin{array}{l}\text { No Answer } \\
\%(n)\end{array}$ \\
\hline I learned a lot about loneliness in the elder & 0 & $12(2)$ & $65(11)$ & $18(3)$ & $6(1)$ \\
\hline $\begin{array}{l}\text { I learned a lot about how to consult patients in terms of social } \\
\text { activity }\end{array}$ & 0 & $6(1)$ & $24(4)$ & $29(5)$ & $4 \mid(7)$ \\
\hline I learned a lot about self-care & 0 & $12(2)$ & $59(10)$ & $24(4)$ & $6(1)$ \\
\hline $\begin{array}{l}\text { I learned a lot about how to advise patients in the use of home } \\
\text { remedies }\end{array}$ & 0 & 0 & $4 I(7)$ & $35(6)$ & $24(4)$ \\
\hline $\begin{array}{l}\text { I am able to implement the training methods into my daily } \\
\text { professional routine }\end{array}$ & 0 & $12(2)$ & $59(10)$ & $29(5)$ & 0 \\
\hline Individual Aspects of the Training & $\begin{array}{l}\text { Dissatisfied \% } \\
\text { (n) }\end{array}$ & $\begin{array}{c}\text { Somewhat } \\
\text { Dissatisfied \% (n) }\end{array}$ & $\begin{array}{l}\text { Somewhat } \\
\text { Satisfied \% (n) }\end{array}$ & $\begin{array}{c}\text { Fully } \\
\text { Satisfied \% } \\
\text { (n) }\end{array}$ & $\begin{array}{l}\text { No Answer } \\
\%(n)\end{array}$ \\
\hline Information content & 0 & 0 & $47(8)$ & $4 \mid(7)$ & $12(2)$ \\
\hline Presentation (Didactics, etc.) & 0 & 0 & $47(8)$ & $4 \mid(7)$ & $12(2)$ \\
\hline Opportunities to participate & 0 & 0 & $24(4)$ & $65(11)$ & $12(2)$ \\
\hline Work atmosphere & 0 & 0 & $12(2)$ & $77(13)$ & $12(2)$ \\
\hline Practicality/applicability & 0 & 0 & $4 I(7)$ & $41(7)$ & $18(3)$ \\
\hline Organization & 0 & 0 & $29(5)$ & $59(10)$ & $12(2)$ \\
\hline Material & 0 & 0 & $24(4)$ & $65(11)$ & $12(2)$ \\
\hline Cooperative communication/exchange & 0 & $6(1)$ & $24(4)$ & $59(10)$ & $12(2)$ \\
\hline Videos showing two different communication styles & 0 & $12(2)$ & $24(4)$ & $53(9)$ & $12(2)$ \\
\hline $\begin{array}{l}\text { Small-group exercise in social activity counseling, using } \\
\text { motivational communication style }\end{array}$ & 0 & $12(2)$ & $29(5)$ & $29(5)$ & $29(5)$ \\
\hline Practice of applying home remedies & 0 & 0 & $18(3)$ & $71(12)$ & $12(2)$ \\
\hline How satisfied are you with the workshop on the whole & 0 & 0 & $47(8)$ & $41(7)$ & $12(2)$ \\
\hline
\end{tabular}

readiness or capacity of MAs and GPs to attend. One option worth considering may be to offer a 2-day workshop instead, for example by cutting the hours per day to three hours each. This could also provide more space for exchange among MAs, which one MA had mentioned had been lacking. Another solution could be to make use of the blended learning concept, eg, to combine preparatory online educational programs with the in-class workshop. ${ }^{22}$

\section{Modifications Related to the Acceptance of the Training Regarding GPs' Evaluation}

GPs' evaluation shows that the workshop was widely accepted and the learning objectives were achieved. The biggest problem seemed to be eliciting a spiritual history. For some participants, initiating a conversation on spirituality with the patient made them feel odd, uncomfortable, self-conscious and rather insisting. This result is consistent with results found in 
the existing literature pertaining to spiritual history taking and spiritual care. ${ }^{11,14,23-26}$ In the literature, we also often find that physicians react positively and openly to patients for addressing spiritual issues first, yet refrain from initiating the first step. $^{27,28}$

However, as Frick et al and Puchalski and Romer stated, it is precisely the interventional effect of proactively asking the patient about his or her spirituality that may open the door for new and unexpected coping resources. ${ }^{19,21,31}$ Taking a spiritual history gives the patient " ... permission to talk about those kinds of [spiritual] issues". ${ }^{19}$ From current literature, we know that training in spiritual assessment reduces the barriers that exist for GPs to proactively address spiritual needs among their patients. $^{11,26,30,32}$ The work with standardized patients in a simulated consultation setting was very well received by all participants. In prior studies, training communication skills ${ }^{18}$ in simulated consultation has not always achieved clear results. ${ }^{29}$ On the other hand, previous studies demonstrated that GPs who practiced communication skills in simulated patient settings gained more confidence in their ability to lead a spiritual/existential conversation with their patients. $^{11,30}$

\section{Regarding MAs' Evaluation}

MAs' evaluation showed that $88 \%(n=15)$ were generally satisfied with the training. However, it seemed that some MAs were unsure about how to implement the different tasks into practice. Consequently, methods to strengthen the reflection about implementation are needed. Generally, it is crucial that GPs and MAs interact optimally, in order to understand the role of the other and the potential difficulties in implementing the holistic care program in their respective tasks. Existing literature has confirmed that interprofessional training raises awareness for the specific roles of the different health care providers. $^{5,19}$

\section{Limitations}

Our major limitation was the small sample size. However, HoPES3 is an exploratory study and the effects of the holistic training are yet in the process of being tested. Another limitation was the fact that our sample consisted of GPs and MAs who may have been biased in favor of holistic primary care, since participation in the study was voluntary.

\section{Conclusion}

To our knowledge, this is the first interprofessional, holistic care workshop in a primary care setting in Germany, training GPs in taking a spiritual history and MAs in counselling skills to advise patients on social activities and the use of home remedies. All in all, the training concept was feasible and the acceptance among participants was high. Yet we suggest some modifications in order to improve the training, such as more reflection on the implementation process and the interdisciplinary interaction between GPs and MAs.

\section{Data Sharing Statement}

The authors do not intend to share individual de-identified participant data. Study results will be published in peerreviewed journals, preserving the rights of patients, other participants, and cited authors. Data will be shown during scientific congresses, too. Submissions are scheduled for 2021 to 2024 . Time of availability is limited by the chosen journals' policy.

\section{Ethical Approval}

The study was registered in the German Clinical Trials Register (DRKS00015696). It complied with all the relevant national regulations, institutional policies, is in accordance the tenets of the Helsinki Declaration, and has been approved by the Ethical Committee of the University of Heidelberg (S-730/2018).

\section{Informed Consent}

Informed consent was obtained from all individuals included in this study.

\section{Author Contributions}

All authors made a significant contribution to the work reported, whether that is in the conception, study design, execution, acquisition of data, analysis and interpretation, or in all these areas; took part in drafting, revising or critically reviewing the article; gave final approval of the version to be published; have agreed on the journal to which the article has been submitted; and agree to be accountable for all aspects of the work.

\section{Funding}

The study is funded by the German Federal Ministry of Education and Research (funding code 01GL1803). 


\section{Disclosure}

The authors report no conflicts of interest in this work.

\section{References}

1. Buck HG, Lee CS, Moser DK, et al. Relationship between self-care and health-related quality of life in older adults with moderate to advanced heart failure. $J$ Cardiovasc Nurs. 2012;27(1):8-15. doi:10.1097/JCN.0b013e3182106299

2. Strassner C, Frick E, Stotz-Ingenlath G, et al. Holistic care program for elderly patients to integrate spiritual needs, social activity, and self-care into disease management in primary care (HoPES3): study protocol for a cluster-randomized trial. Trials. 2019;20(1):364. doi:10.1186/s13063-019-3435-z

3. Gonzalez AI, Schmucker C, Nothacker J, et al. Health-related preferences of older patients with multimorbidity: an evidence map. BMJ Open. 2019;9(12):e034485. doi:10.1136/bmjopen-2019-034485

4. Hajek A, Brettschneider C, Eisele M, et al. Does transpersonal trust moderate the association between chronic conditions and general practitioner visits in the oldest old? Results of the AgeCoDe and AgeQualiDe Study. Geriatr Gerontol Int. 2019;19(8):705-710. doi:10.1111/ggi.13693

5. Puchalski CM, Blatt B, Kogan M, Butler A. Spirituality and health: the development of a field. Acad Med. 2014;89(1):10-16. doi:10.1097/ACM.000000000000083

6. Best M, Butow P, Olver I. Creating a safe space: a qualitative inquiry into the way doctors discuss spirituality. Palliat Support Care. 2016;14(5):519-531. doi:10.1017/S1478951515001236

7. Monroe MH, Bynum D, Susi B, et al. Primary care physician preferences regarding spiritual behavior in medical practice. Arch Intern Med. 2003;163(22):2751-2756. doi:10.1001/archinte.163.22.2751

8. Reeve J. Interpretive medicine: supporting generalism in a changing primary care world. J R Coll Gen Pract Occas Pap. 2010;(88):1.

9. Appleby A, Swinton J, Wilson P. Spiritual care training and the GP curriculum: where to now? Educ Prim Care. 2019;30(4):194-197. doi:10.1080/14739879.2019.1600383

10. Best M, Aldridge L, Butow P, Olver I, Price M, Webster F. Assessment of spiritual suffering in the cancer context: a systematic literature review. Palliat Support Care. 2015;13(5):1335-1361. doi:10.1017/S1478951514001217

11. Assing-Hvidt E, Ammentorp J, Søndergaard J, Timmermann C, Hansen DG, Hvidt NC. Developing and evaluating a course programme to enhance existential communication with cancer patients in general practice. Scand J Prim Health Care. 2018;36(2):142-151. doi:10.1080/02813432.2018.1459235

12. Best M, Butow P, Olver I. Why do we find it so hard to discuss spirituality? A qualitative exploration of attitudinal barriers. $J$ Clin Med. 2016;5(9):77. doi:10.3390/jcm5090077

13. Appleby A, Wilson P, Swinton J. Spiritual care in general practice: rushing in or fearing to tread? An integrative review of qualitative literature. J Relig Health. 2018;57(3):1108-1124. doi:10.1007/ s10943-018-0581-7

14. Taverna M, Sattel H, Berberat P, Frick E. A survey on the integration of spiritual care in medical schools from the German speaking faculties. Adv Med Educ Pract. 2019;10:1009-1019. doi:10.2147/ AMEP.S224679

15. Amelung V, Chase D, Reichert A. Leadership in integrated care. In: Amelung V, Stein V, Goodwin N, Balicer R, Nolte E, Suter E, editors. Handbook Integrated Care. Cham: Springer International Publishing; 2017:221-236.
16. Medical Research Council. Available from: https://mrc.ukri.org/ documents/pdf/complex-interventions-guidance/. Accessed November 10, 2019.

17. Bar-Sela G, Schultz MJ, Elshamy K, et al. Training for awareness of one's own spirituality: a key factor in overcoming barriers to the provision of spiritual care to advanced cancer patients by doctors and nurses. Palliat Support Care. 2019;17(3):345-352. doi:10.1017/ S147895151800055X

18. Hashim MJ. Patient-centered communication: basic skills. Am Fam Physician. 2017;95(1):29-34.

19. Puchalski CM, Romer AL. Taking a spiritual history allows clinicians to understand patients more fully. J Palliat Med. 2000;3(1):129-137. doi:10.1089/jpm.2000.3.129

20. Mendip HC. Health connections mendip; 2019. Available from: www.healthconnectionsmendip.org. Accessed October 7, 2019.

21. Frick E, Riedner C, Fegg MJ, Hauf S, Borasio GD. A clinical interview assessing cancer patients' spiritual needs and preferences. Eur $J$ Cancer Care. 2006;15(3):238-243. doi:10.1111/j.13652354.2005.00646.x

22. Liu Q, Peng W, Zhang F, Hu R, Li Y, Yan W. The effectiveness of blended learning in health professions: systematic review and meta-analysis. J Med Internet Res. 2016;18(1):e2. doi:10.2196/ jmir.4807

23. Best M, Butow P, Olver I. Do patients want doctors to talk about spirituality? A systematic literature review. Patient Educ Couns. 2015;98(11):1320-1328. doi:10.1016/j.pec.2015.04.017

24. Culatto A, Summerton CB. Spirituality and health education: a national survey of academic leaders UK. J Relig Health. 2015;54 (6):2269-2275. doi:10.1007/s10943-014-9974-4

25. Balboni MJ, Sullivan A, Enzinger AC, et al. Nurse and physician barriers to spiritual care provision at the end of life. J Pain Symptom Manage. 2014;48(3):400-410. doi:10.1016/j.jpainsymma n.2013.09.020

26. Best M, Butow P, Olver I. Doctors discussing religion and spirituality: a systematic literature review. Palliat Med. 2016;30(4):327-337. doi: $10.1177 / 0269216315600912$

27. Best M, Butow P, Olver I. Spiritual support of cancer patients and the role of the doctor. Support Care Cancer. 2014;22(5):1333-1339. doi:10.1007/s00520-013-2091-1

28. Anandarajah G, Roseman J, Lee D, Dhandhania N. A 10-year longitudinal study of effects of a multifaceted residency spiritual care curriculum: clinical ability, professional formation, end of life, and culture. J Pain Symptom Manage. 2016;52(6):859-872.e851. doi:10.1016/j.jpainsymman.2016.06.006

29. Selman LE, Brighton LJ, Sinclair S, et al. Patients' and caregivers' needs, experiences, preferences and research priorities in spiritual care: a focus group study across nine countries. Palliat Med. 2018;32(1):216-230. doi:10.1177/0269216317734954

30. Thiel MM, Luff D, Kerr E, Robinson MR, Meyer EC. Health care professional's reflections on their learning as spiritual generalists and integration into practice. J Contin Educ Health. 2020;40(4):228-234.

31. Fuchs JR, Fuchs JW, Hauser JM, Coors ME. Patient desire for spiritual assessment is unmet in urban and rural primary care settings. BMC Health Serv Res. 2021;21(1):289.

32. Jones KF, Paal P, Symons X, Best MC. The content, teaching methods and effectiveness of spiritual care training for healthcare professionals: A mixed-methods systematic review. J Pain Symptom Manage. 2021:in press. 
Video abstract

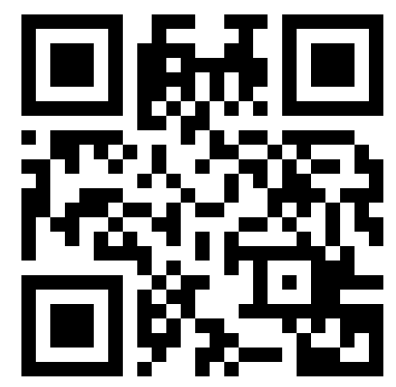

Point your SmartPhone at the code above. If you have a QR code reader the video abstract will appear. Or use: https://youtu.be/hcz-CKYOK8s

\section{Publish your work in this journal}

The Journal of Multidisciplinary Healthcare is an international, peerreviewed open-access journal that aims to represent and publish research in healthcare areas delivered by practitioners of different disciplines. This includes studies and reviews conducted by multidisciplinary teams as well as research which evaluates the results or conduct of such teams or healthcare processes in general. The journal covers a very wide range of areas and welcomes submissions from practitioners at all levels, from all over the world. The manuscript management system is completely online and includes a very quick and fair peer-review system. Visit http://www.dovepress.com/testimonials. php to read real quotes from published authors. 